\title{
Comparison of data from complementary seismograph networks in a mining district
}

\author{
MRG Grobbelaar Council for Geoscience, South Africa \\ D Birch Council for Geoscience, South Africa
}

A Cichowicz Council for Geoscience, South Africa

\begin{abstract}
South Africa has embarked on the installation of dense local surface networks within a number of mining regions in order to create a unique situation where data from an event can be recorded by three separate networks; at distances of: $500 \mathrm{~km}$ by the national seismograph network, $4 \mathrm{~km}$ by the local network and $100 \mathrm{~m}$ by the mining networks. The data can be used for hazard at the stope and hazard within the region and, thus, trends can be identified in order to assist in the investigation and mitigation of seismic related accidents. This is a first for the country.

The ML5.5 earthquake on 5 August 2014, provided an ideal opportunity for collaboration and comparison between the local surface and mining networks, especially since each network has its own unique challenges due to equipment specifications and capabilities. Thus, such a comparison would help quantify these differences.

The locations of the earthquakes, as well as other spectral parameters, obtained by each network were investigated. Many of the parameters were very similar, such as the estimated $M_{w}$ magnitudes from both the networks. Similarly, the scalar seismic moments offered by both networks are comparable, but with a tendency to underestimate by the mining network in comparison to the local surface network. In addition, the radiated seismic energy estimated by both networks follow the same trend, however, significant scattering of the estimated energy is observed at small values.

The spatial patterns of seismicity associated with the aftershocks of the $M_{L} 5.5$ earthquake were compared and both networks reveal a very similar pattern, however, the mining network delineated the fault with a higher accuracy than the local surface network.
\end{abstract}

Keywords: comparison, spectral parameters, mining, seismograph networks

\section{Introduction}

The Council for Geoscience (CGS) operates and maintains the South African National Seismograph Network (SANSN), which consists of permanently installed three-component seismograph stations scattered around South Africa (Saunders et al. 2008). Figure 1 shows a map of the locations of these stations. The SANSN monitors the seismic activity in and around the country, and can detect/record earthquakes up to hundreds of kilometres away. The seismicity recorded in South Africa is mainly located in the gold mining regions (Figure 2(a)). Therefore, the CGS embarked on a number of initiatives to install dense local seismograph networks in and around the mining regions that have higher levels of seismicity. These areas are indicated in Figures 2(b) to 2(d). 


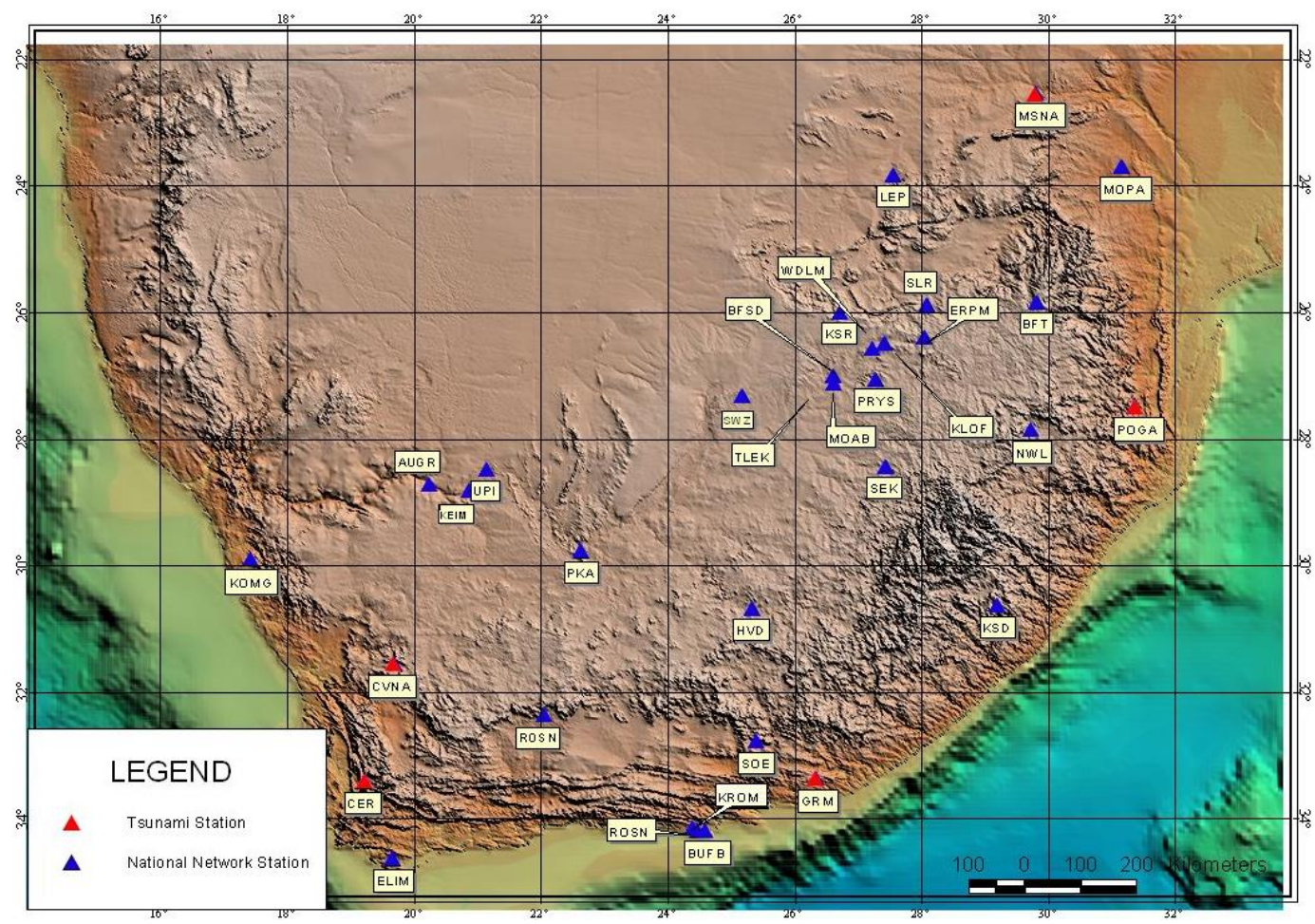

Figure 1 Map of SANSN stations scattered throughout South Africa as indicated by the triangles. Five of the stations send continuous data to the Indian Ocean Tsunami Warning Centres, as indicated by the red triangles

(d)

(a)
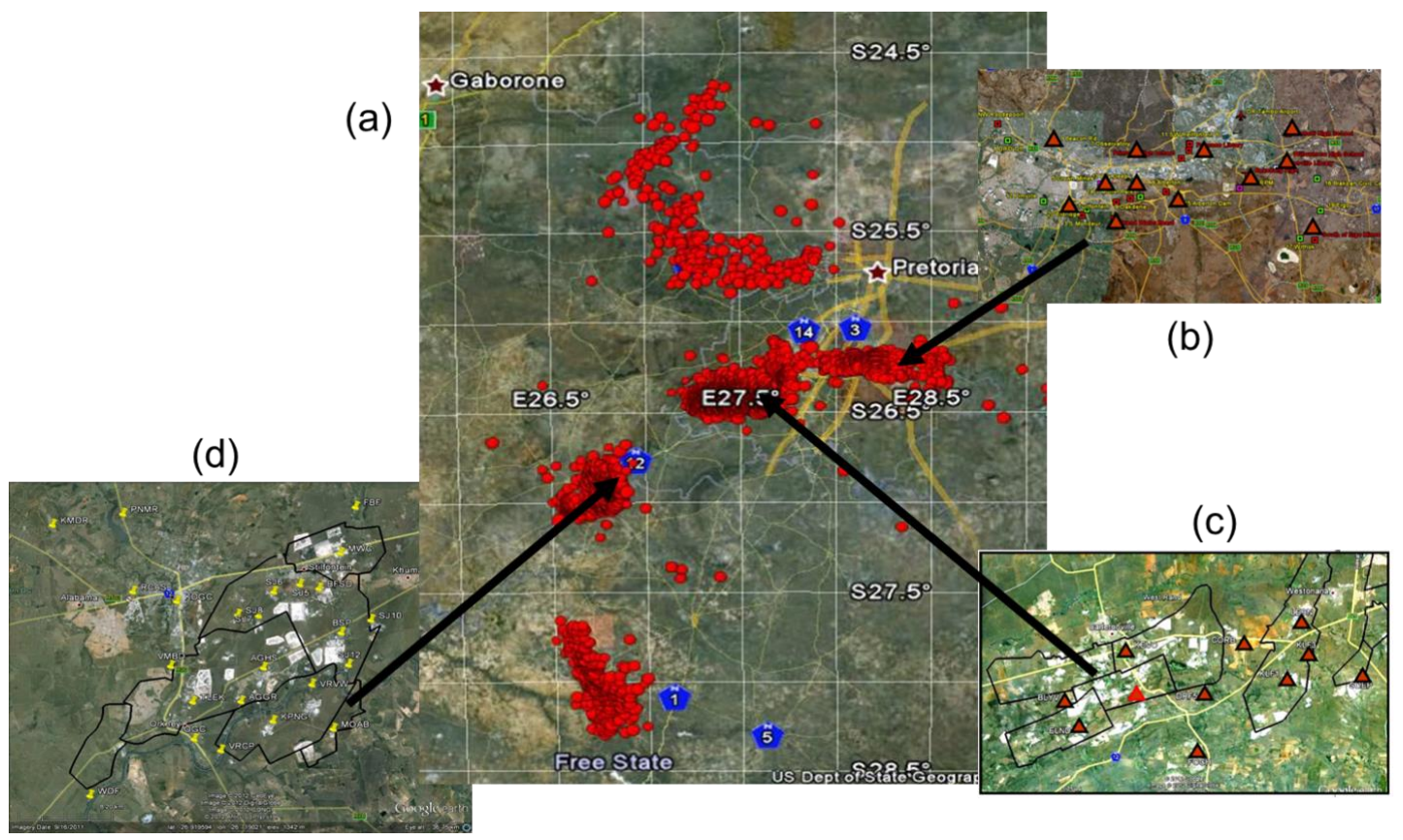

Figure 2 (a) Map of the seismicity within South Africa predominantly around the gold mining regions, with dense local seismograph networks installed in and around: (b) Johannesburg; (c) Carletonville; and, (d) Klerksdorp

This paper focuses on the data from the local network that was installed on the surface within the Klerksdorp mining region (Figure 2(d)) and compares it with the data from the stations installed independently underground within the mines. The aim is to highlight the areas where the mining and local surface networks complement each other to provide a unique situation of earthquake monitoring. 
Each of the local surface networks was installed with a specific research aim in mind. The local network in Johannesburg was installed in order to monitor the fluid induced seismicity caused by the ingress of water into historical mines (Cichowicz et al. 2010). The Carletonville local network was installed because of the seismic activity in the region, driven by mining and tectonic activity, which is still fairly high. The Klerksdorp local network was installed because the area had experienced, at the time, the largest mining related earthquake recorded in South Africa, $\mathrm{M}_{\mathrm{L}} 5.3$, in 2005. In 2014, this region experienced yet another large earthquake, which surpassed the magnitude of the earthquake in 2005 , and is now the largest recorded mine related earthquake in South Africa with a $\mathrm{M}_{\mathrm{L}}$ of 5.5 .

\section{Methodology}

Twenty five seismograph stations were installed in and around the Klerksdorp region in shallow surface vaults. After consultations with a number of companies and comparisons of their products, Kinemetrics products were chosen. Their equipment had the best mean time between failures and the lowest power consumption, which for unmanned remote stations is very important. Refer to Figure 3 for an example of a typical installation.

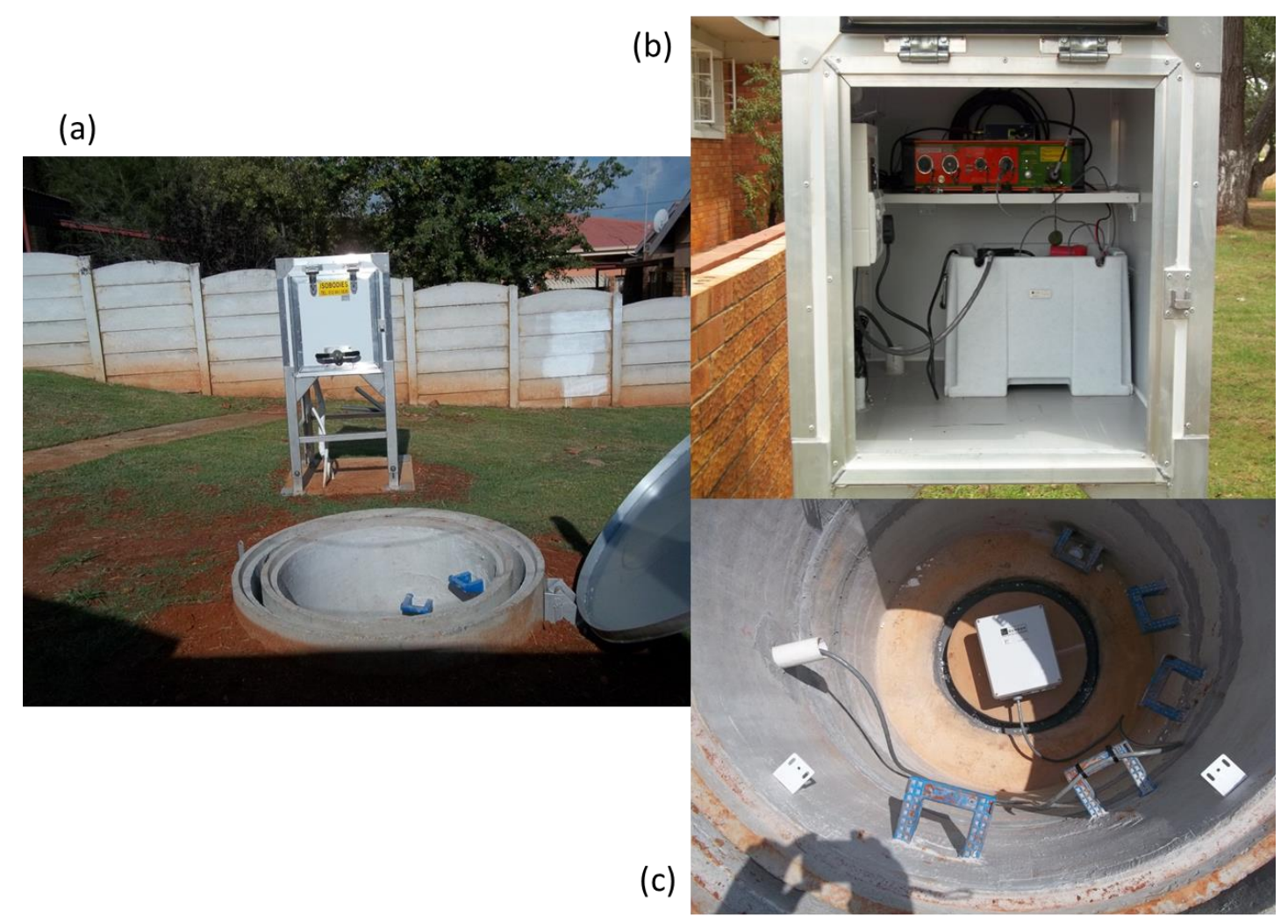

Figure 3 Photo of: (a) a typical seismograph station installation; (b) the backup battery pack (white) and the data acquisition module (orange); and, (c) the sensor placed within a 1-2 m deep concrete vault

Figures 3(a) to 3(c) show the station setup used for each site within the local surface networks. The sensor is placed on a podium inside an insulated vault that is approximately 1-2 $\mathrm{m}$ deep depending on the bedrock and soil conditions at the site. The electronics responsible for data acquisition and transmission are housed in an insulated container on the surface with the cables fed through piping underground. The instrumentation used was:

- Sensor:

Kinemetrics EpiSensor ES-T.

- Data logger: Kinemetrics Quanterra Q330. 
- Modem: Multenet broadband router.

- Battery charger: Hawkins ABC1220.

- Batteries: First national battery: excise 102ah.

The Antelope software (Antelope 2014) was chosen as it is compatible with both the new and existing sets of equipment, and has been proven, across the world, to operate under a number of different network configurations and environments. The software is also well established and is tested and upgraded on a regular basis.

Key specifications of the sensor (such as frequency range of $D C(0 \mathrm{~Hz})$ to $200 \mathrm{~Hz}$ ), data logger and the Antelope data acquisition and processing software can be found on the Kinemetrics website (Kinemetrics Inc. ( 2016 ).

In addition, the choice of sensors had to be complementary to those of the mining networks to ensure a wide range of frequencies are covered. Typically, mining networks are equipped with a combination of 4.5 and $14 \mathrm{~Hz}$ geophones and accelerometers, which are designed to locate small, high frequency seismic events and for calculating the seismic source parameters of these events (Cichowicz 2001). However, these are not suitable for recording low-frequency seismic signals related to larger seismic events $\left(M_{w}>3\right)$, and mining networks are unable to monitor the ground motion on the surface, which contributes significantly to surface damage.

Figures 4 and 5 show the normalised displacement spectrum of Brune's model with the high frequency decay $f^{-2}$ where ' $f$ ' is the frequency (Brune 1970, 1971) for the local magnitudes ranging between 1.0 and 3.0, as well as static stress drop between 0.01 and $100 \mathrm{MPa}$. In Figure 4, the blue area highlights the frequency range where mining networks do not accurately record ground motion due to sensor limitations and similarly, in Figure 5, it highlights the range of frequencies where the local surface network does not accurately record ground motion due to their sensor limitations. Thus, the $4.5 \mathrm{~Hz}$ geophone used by the mining networks is suitable for the estimation of the spectral plateau for $M_{w}=1$ and almost for all $M_{w}=2$, however, $M_{w}=2.5$ and 3 are only recorded well for large stress drops. The sensors used by the local surface network are capable of recording the full spectrum for local magnitudes ranging between 1.5 and 6.0 and, thus, can supplement the data from the mining networks. 


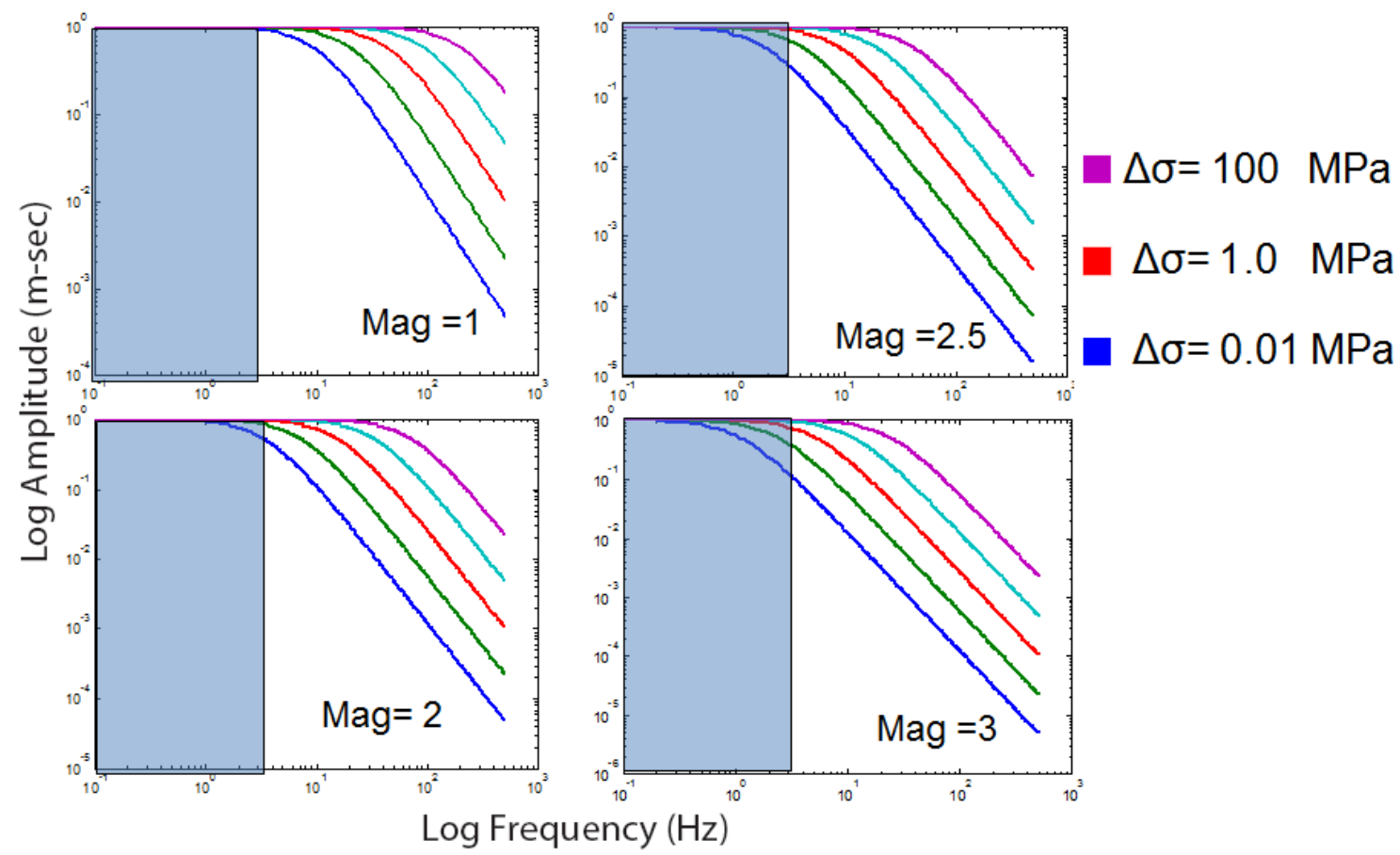

Figure 4 Limits of applicability of $4.5 \mathrm{~Hz}$ geophones used by mining networks. This geophone is suitable for estimation of the spectral plateau for Mag $=1$ and almost for all Mag $=2$. However, Mag = 2.5 and 3 are only well defined for large stress drops. (Mag refers to $M_{w}$ magnitude)

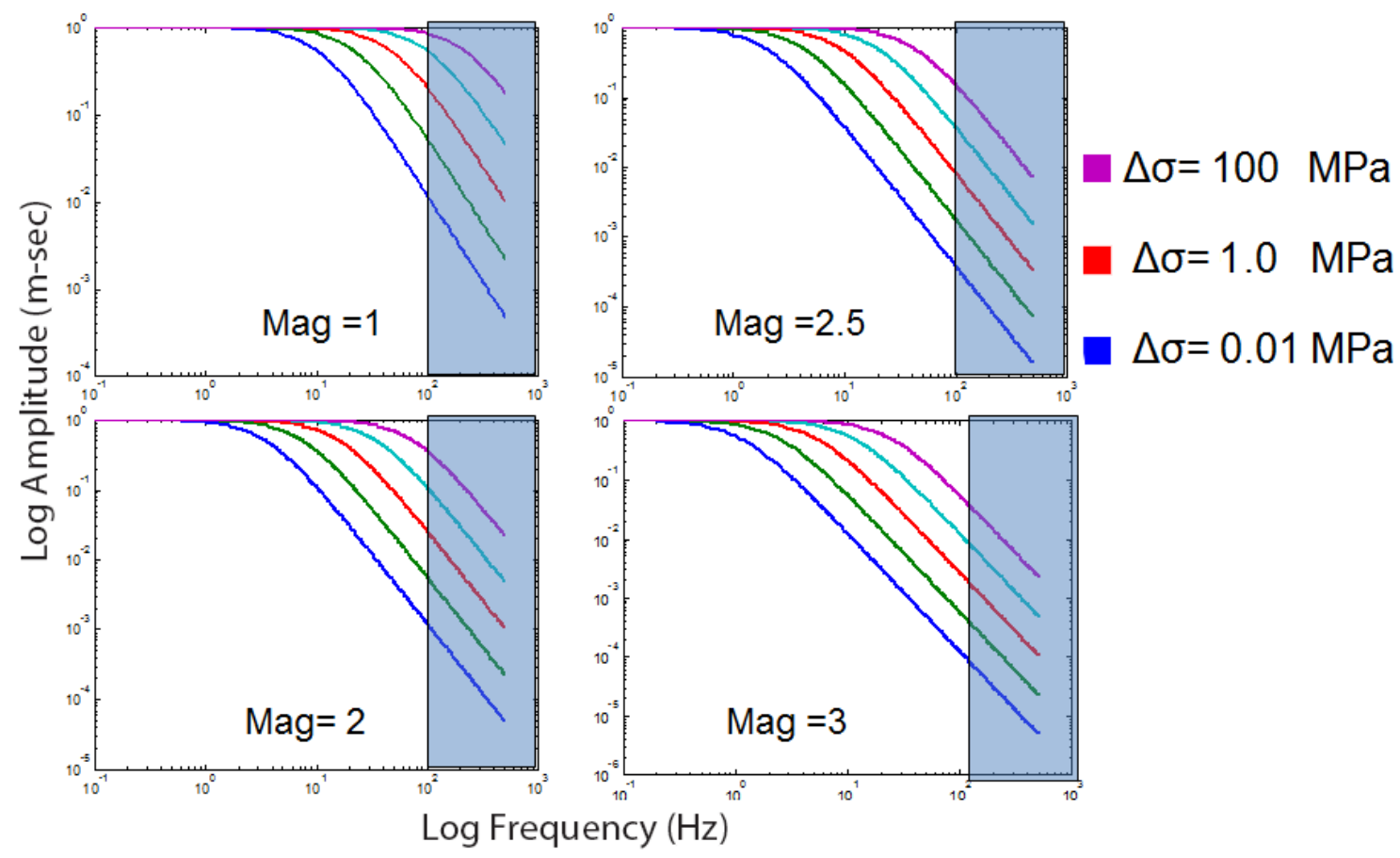

Figure 5 The CGS sensors will record the full spectrum from $M_{w} 1.5$ to 6.0. Strong ground motion accelerometers have a frequency range from $D C(0 \mathrm{~Hz})$ to $200 \mathrm{~Hz}$. (Mag refers to $M_{w}$ )

The CGS received a catalogue of processed events from the mining network for a period during which the CGS network was operational, therefore, a comparison of databases was possible. A comparison of various spectral parameters was performed.

Unpublished data processing software, developed in-house by Cichowicz and Birch (2012), was used to calculate the scalar seismic moment, moment magnitude $\left(\mathrm{M}_{\mathrm{w}}\right)$, radiated seismic energy, corner frequency, 
source radius and the apparent and static stress drops. Scalar seismic moments for P- and S-wave corner frequencies, $f_{O P}$ and $f_{0 s}$, are taken from the respective amplitude spectra. The respective corner frequencies were then used to determine the fault radius, r, after both the Brune $(1970,1971)$ and Madariaga (1976, 1979) models. Assuming a complete stress release, in the context of a kinematic source model, Brune's model estimates for the stress drop are given by Keilis-Borok (1959) and Brune (1970 and 1971). Models used for static stress drop estimations assume a fixed value for the rupture velocity and represent a uniform reduction in shear stress acting to produce seismic slip over a circular fault. The estimation of the magnitude $M_{w}$, is based on the seismic moment calculated from Mo (Hanks \& Kanamori 1979).

\section{$3 \quad$ Results}

The occurrence of the ML5.5 earthquake, on 5 August 2014, provided an ideal opportunity to compare the data obtained from the two networks. The following comparison was based mainly on the aftershocks associated with the main event.

The relationship between Mine $M_{w}$ and CGS $M_{w}$ magnitudes $\left(M_{w}{ }^{M i n e}=0.94\left(M_{w}{ }^{C G S}\right)-0.35\right)$, obtained using data from the mining network and from the local surface network, is presented in Figure 6 . This relation is very close to one, therefore, for practical purposes both the $M_{w}$ magnitudes can be used interchangeably. It should be noted that, Figure 6 does not include the magnitude $M_{\llcorner} 5.5$ event because the $4.5 \mathrm{~Hz}$ geophones of the mining network were not able to adequately resolve the low-frequency plateau of the displacement spectrum for this event.

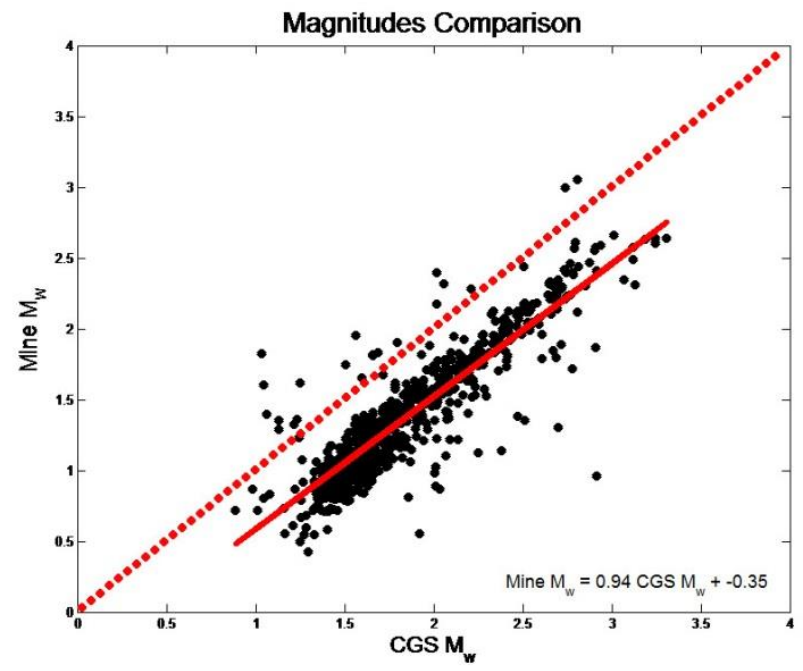

Figure 6 Relationship between the $M_{w}$ magnitude estimations obtained by the two networks, the dotted line represents the 1:1 relationship. The magnitudes range from 0.8 to 3.5 , which is the range of events recorded by the local surface network

By excluding this outlier, Figure 6 portrays a more realistic relationship $\left(\mathrm{M}_{\mathrm{w}}{ }^{\mathrm{Mine}}=0.94\left(\mathrm{M}_{\mathrm{w}}{ }^{\mathrm{CGS}}\right)-0.35\right)$ between the $M_{w}$ estimations obtained by the mine's and CGS' local networks.

The relationship between seismic energy of the mining network S-wave and the local surface network SV-wave is presented in Figure 7. The range of the SV-wave energy is from 103 to 1,012 J. Both estimations scatter symmetrically around the red line indicated in Figure 7. This indicates that there is no systematic shift between the networks. In other words, both networks similarly record the frequency content responsible for the estimation of seismic energy for seismic events with magnitude greater than or equal to 1 . Additionally, the estimation of seismic energy is very sensitive to the attenuation correction being used and it could be concluded that, since there is such a close correlation between the networks, the attenuation corrections used by the networks, although different, are suitable. 

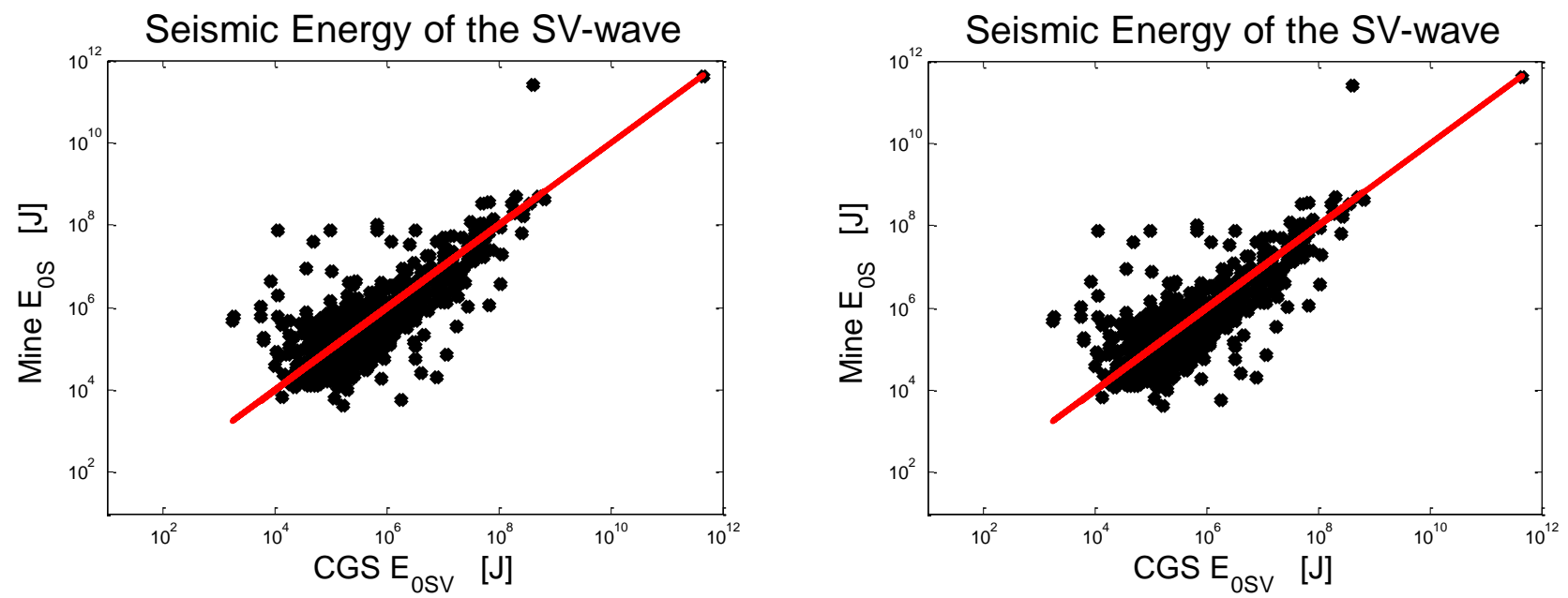

Figure 7 Relationship between the radiated seismic energy estimation obtained by two networks using the S-wave signal where the red line indicates a one-to-one relationship

The spatial patterns of seismicity associated with the aftershocks of the $M_{\llcorner} 5.5$ earthquake are shown in Figure 8 for the time window: 2014/05/08-2014/05/25. The size of the dots is proportional to $M_{w}$ magnitude. The locations of the events recorded by both networks reveal a very similar pattern. The mine network delineates the fault with a higher accuracy but both networks offer the same distribution in plan view and section view. 

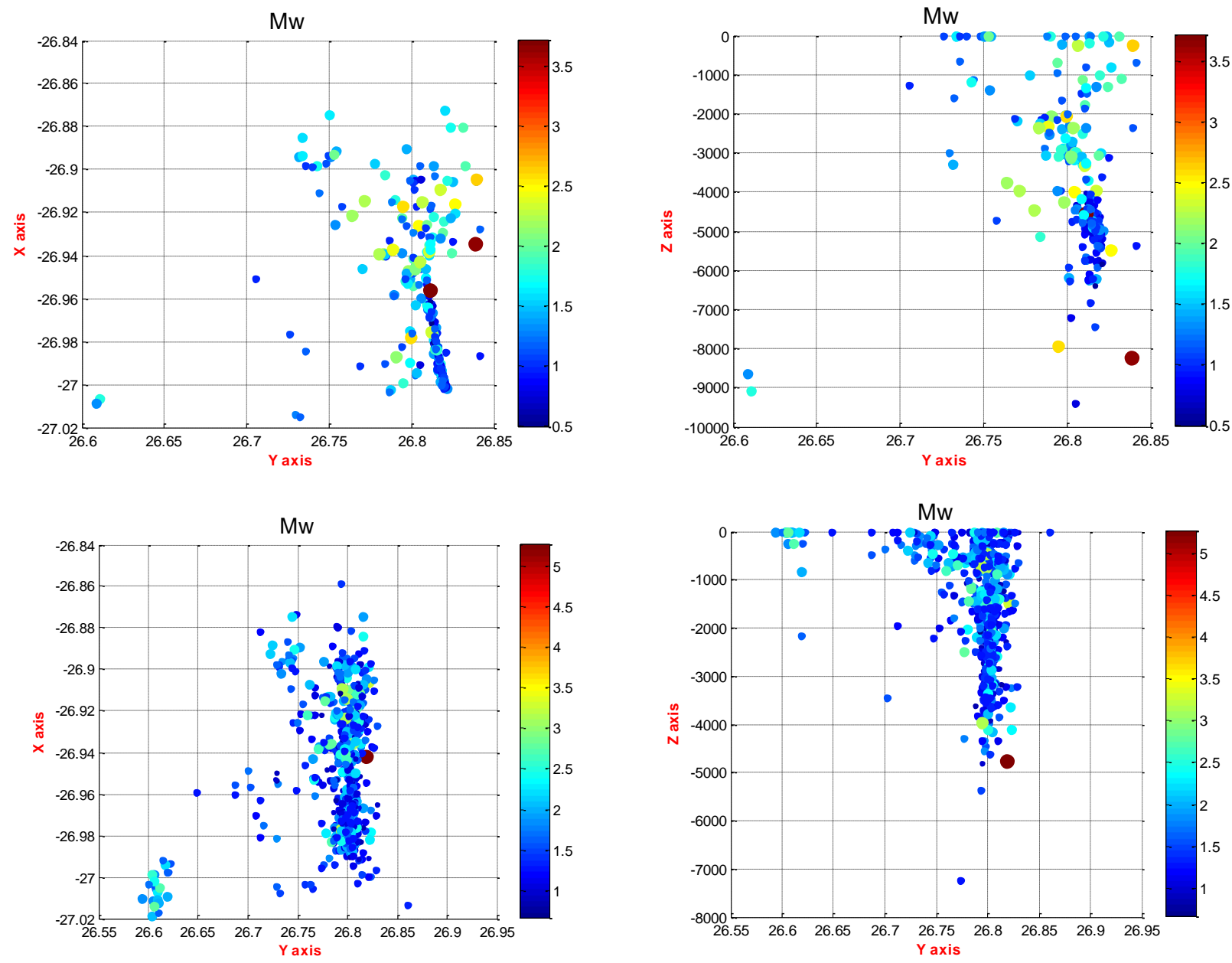

(a)

(b)

Figure 8 (a) Plan view and (b) vertical cross-section ( $E-W$ versus depth), of the locations of aftershocks in the Klerksdorp area for the time window from 5 August 2014 to 25 August 2014. (Top) Data for the mining network. (Bottom) Data for the local surface network

\section{Conclusion}

The estimated $M_{w}$ magnitudes from the two networks are for practical purposes, comparable $\left(\mathrm{M}_{\mathrm{w}}{ }^{\mathrm{Mine}}=0.94\left(\mathrm{M}_{\mathrm{w}}{ }^{\mathrm{CGS}}\right)-0.35\right)$. Similarly, the scalar seismic moments offered by both networks are comparable, but with a tendency to be underestimated by the mining network in comparison to the local surface network. In addition, the radiated seismic energy estimated by both networks follow the same trends, however, in the range varying from 103 to 1,012 J, significant scattering of the estimated energy value is observed.

The locations obtained by the mining network can be used as a reference for the local surface network, especially since the locations from the mining network provide a sharp delineation of the geological features in the area while the local surface network data is much less pronounced.

In conclusion, the new local surface network is fully operational and has been well received by the stakeholders. The importance of the network was highlighted after the ML5.5 earthquake on 5 August 2014, where the data was available and could be merged with mining data in order to better understand the mechanisms of the earthquake. 


\section{Acknowledgement}

This work was sponsored by the Mine Health and Safety Council under project SIM140204: Integration of the South African National Seismograph Network and Database with Mining Networks as per the recommendation in chapter 1 of the Presidential Mine Health and Safety Audit 2008.

The authors thank AngloGold Ashanti for their willingness to share and compare data.

\section{References}

Antelope 2014, Antelope Version 5.4, Environmental Monitoring Software, viewed 23 August 2016, www.kinemetrics.com

Brune, JN 1970, 'Tectonic stress and the spectra of seismic shear waves from earthquakes', Journal of Geophysical Research, vol. 75, pp. 4997-5009.

Brune, JN 1971, 'Correction', Journal of Geophysical Research, vol. 76, p. 5002.

Cichowicz, A 2001, 'Quantification of complex seismic sources', Proceedings of the 5th International Symposium on Rockbursts and Seismicity in Mines (RaSiM5), Southern African Institute of Mining and Metallurgy, Johannesburg, pp. 91-97.

Cichowicz, A \& Birch, D 2012, Enabling output 2: Estimation of Seismic Source Parameters part of the project: Fluid-Induced Seismicity in the Central Basin Area: Ground Motion Prediction and the Development of an Early Warning System for Risk Reduction, commissioned by the Mine Health and Safety Council, project number, SIM 11-02-01.

Cichowicz, A, Kgaswane, E, van Aswegen, G, Adamos, P, Birch, D, Jele, V, Kometsi, R, Prasad, K, Saunders, I, Strasser, F, Tabane, L \& Zulu, B 2010, Monitoring Seismicity in the Central Rand and East Rand Goldfield - Mine-Flooding Induced Seismicity, report no. 2010-0056, part of the Strategic Water Management Project commissioned by the Department of Mineral Resources of South Africa.

Hanks, T \& Kanamori, H 1979, 'A moment magnitude scale', Journal of Geophysical Research, vol. 84, no.B5, pp. $2348-2350$.

Keilis-Borok, V 1959, 'On estimation of the displacement in an earthquake source and of source dimension, Annals of geophysics, vol. 12, pp. 205-214.

Kinemetrics Inc. ${ }^{\odot} 2016$, viewed 23 August 2016, www.kinemetrics.com

Madariaga, R 1976, 'Dynamics of an expanding circular fault', Bulletin of the Seismological Society of America, vol. 66, pp. 639-666.

Madariaga, R 1979, 'On the relation between seismic moment and stress drop in the presence of stress and strength heterogeneity', Journal of Geophysical Research, vol. 84, pp. 2243-2250.

Saunders, I, Brandt, MBC, Steyn, J, Roblin, DL \& Kijko, A 2008, 'The South African National Seismograph Network', Seismological Research Letters, vol. 79, no. 2, pp. 203-210. 